\title{
Reye Syndrome - A Case Report with Review of Literature .
}

\author{
Ghosh A, Pradhan S, Swami R, KC SR, Talwar OP \\ Department of Pathology, Manipal College of Medical Sciences and Manipal Teaching Hospital, Pokhara, Nepal
}

\section{ABSTRACT}

Here we describe a case of Reye syndrome diagnosed at postmortem liver biopsy of a three-year old girl who presented with vomiting, low grade fever for three days and loss of consciousness for 18 hours. Clinically, the differential diagnoses were meningitis, encephalitis and septicemia. No history of past illness or any drug ingestion including aspirin were present. Laboratory investigations indicated a diagnosis of Reye syndrome. The child was given supportive treatment but died after two days of admission and postmortem needle-biopsy of the liver showed microvesicular steatosis consistent with Reye syndrome.

Key words: Microvesicular steatosis, mitochondrial hepatopathy, Reye syndrome, Reye-like syndrome

\section{INTRODUCTION}

Reye syndrome is a potentially fatal disease involving several organs, especially the liver and brain. Reye syndrome presents as a dysfunction of the liver and metabolic encephalopathy in children. It is called a "twophase illness" since, in most cases, it is associated with a previous viral illness. ${ }^{1,2}$ The cause is not exactly known and studies have suggested association with several factors, most importantly a history of prior aspirin ingestion. ${ }^{3}$ However, Reye syndrome is no longer a specific clinicopathological entity but a descriptive term covering a group of heterogeneous disorders of infectious, metabolic, or toxic etiology. ${ }^{4}$ Its incidence has shown a sharp decline in parallel with the decline in the use of aspirin in the pediatric age group. ${ }^{5}$ However, recent literature reveal, that this decline is also related to more accurate modern diagnosis of infectious, metabolic or toxic disease, reducing the percentage of idiopathic or true cases of Reye syndrome. ${ }^{4}$

\section{CASE REPORT}

A three-year old girl was referred to our hospital with low grade fever and repeated episodes of projectile vomiting for three days and loss of consciousness for 18 hours. The child was asymptomatic three days back. The fever was of low grade without chills, rigors or rashes. On examination, there was mild hepatomegaly while the spleen was not palpable. Glasgow Coma

Correspondence:

Dr. Arnab Ghosh

Department of Pathology

Manipal Teaching Hospital

Pokhara, Nepal.

Email: drghosharnab@yahoo.com 
Scale was 6/15 (Eyes 1 Verbal 2 Motor). Systemic examination was normal including absence of icterus, pallor, lymphadenopathy and neck rigidity. The clinical differentials were viral encephalitis, meningitis and septicemia. No history of intake of aspirin or any other drug was found. There was no past history of significant illness. She, the only child of her parents, was fully immunized as per schedule and her developmental milestones were normal. The socioeconomic condition of the family was good and there was no significant family history. The patient was admitted to the Neonatal Intensive Care Unit and treatment started with ceftriaxone, gentamicin, ranitidine, mannitol and dextrose. Peripheral blood counts, serum electrolytes and urine routine were normal. Lumbar puncture revealed increased pressure. Cerebrospinal fluid examination showed low glucose level $(4 \mathrm{mg} / \mathrm{dL}$ ). Liver function study showed normal protein levels, mildly elevated bilirubin level $(1.7 \mathrm{mg} / \mathrm{dl})$ and marked increase in both AST (aspartate aminotransferase) and ALT (alanine aminotransferase ) which were $850 \mathrm{U} / \mathrm{L}$ and $1270 \mathrm{U} / \mathrm{L}$ respectively. Random blood glucose was low $(53 \mathrm{mg} /$ $\mathrm{dL})$. A clinical diagnosis of Reye syndrome was made. The patient was continued on supportive treatment. Subsequently, the child developed seizures along with bilateral papilledema. After 38 hours of admission, the condition deteriorated and she expired. Postmortem needle-biopsy of the liver was sent for histopathology which showed two bits of hepatic tissue with two portal tracts and two central veins. The cytoplasm of the hepatocytes showed microvesicular fatty change with absence of glycogen [negative with Periodic Acid Schiff (PAS) stain]. There was only sparse periportal lymphocytic infiltration. There was no evidence of bile duct proliferation, bile stasis, Kupffer cell proliferation, fibrosis, necrosis, or venous congestion. It was reported as microvesicular steatosis consistent with Reye syndrome.

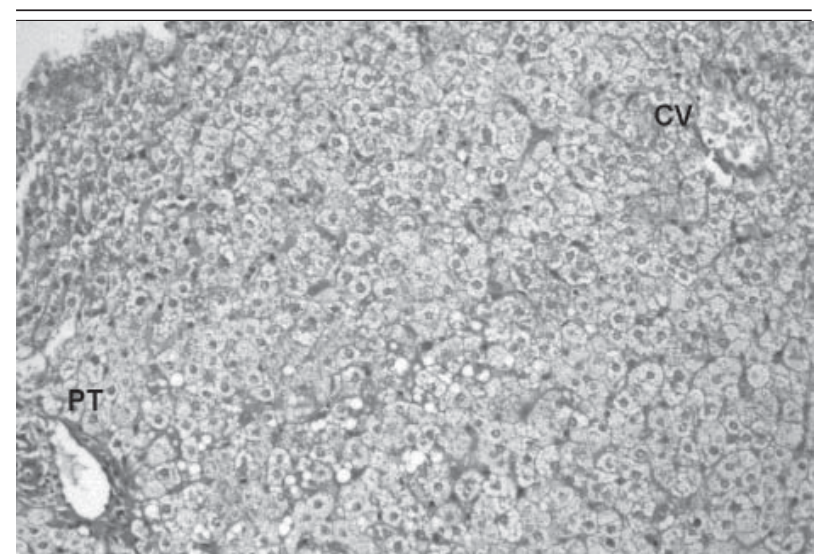

Figure 1. Microvesicular steatosis with minimal inflammation. PT, Portal tract. CV, Central vein. H \& $E, 100 X$

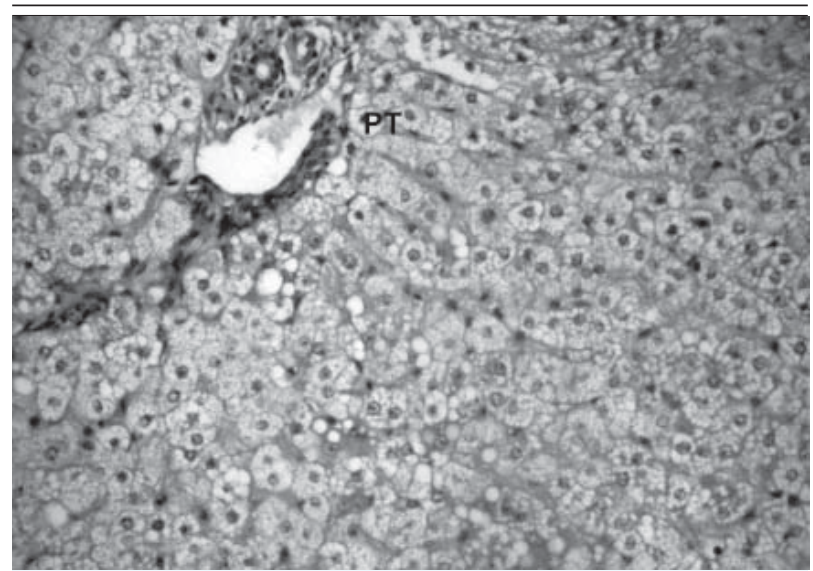

Figure 2. Microvesicular steatosis with minimal inflammation and absence of bile ductular proliferation and bile stasis. PT, Portal tract. H \& E, 200X

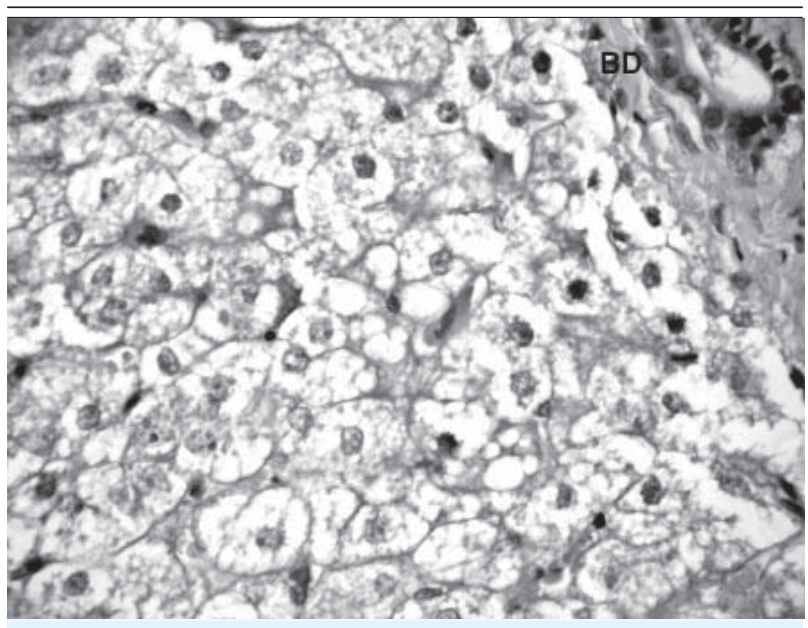

Figure 3. Microvesicular steatosis. BD, Bile duct is normal. H\&E, $1000 X$

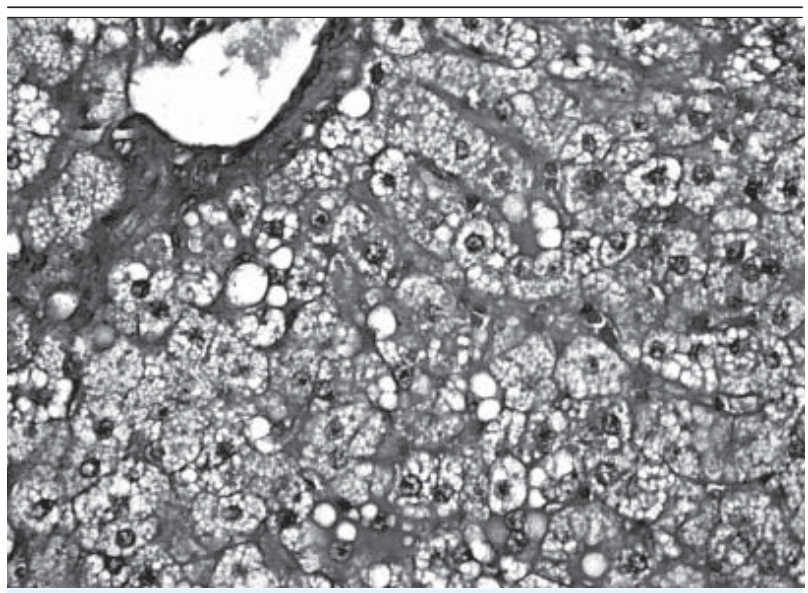

Figure 4. Special stain is negative indicating absence of glycogen. PAS. $400 \mathrm{X}$ 
Ghosh et al. Reye Syndrome - A Case Report with Review of Literature .

\section{DISCUSSION}

In 1963 Reye and his co-workers first described the classical Reye Syndrome which is characterized by acute encephalopathy, fatty degeneration of liver and other viscera, especially brain. ${ }^{1,6}$ In the late 1970s, Reye syndrome showed a marked increase in occurrence in direct relationship with viral epidemics especially due to influenza B and varicella infections in children. This was linked with prior use of aspirin and paracetamol in these patients. By 1988 the incidence had fallen dramatically due to awareness of its association with aspirin and today this disorder is rare. ${ }^{2}$ However, this illness may occur in the absence of exposure to salicylate, ${ }^{7}$ as in this case. This syndrome is reported from all over the world. ${ }^{1}$ Till date, only one case was reported from Nepal in 2003. ${ }^{8}$ Most cases are seen in the $4-12$ years age range and almost exclusively below 15 years of age. ${ }^{2,7}$ There is no gender difference. However, rural populations are seen to be affected more. ${ }^{2}$ Also, there are instances of familial occurrence. ${ }^{1}$ The exact etiology however remains unclear. There are instances of association with viral infection (influenza B, varicella, parainfluenza, reovirus, ECHO virus, adenovirus); toxins (Asperigillus flavus, ackee fruit, aflatoxin, isopropyl alcohol, pesticides, insect repellants); drugs (salicylates, valproate, phenothiazines and antiemetics). 1,4,7,9,10 The pathophysiology involves generalized loss of mitochondrial function leading to disturbances in fatty acid and carnitine metabolism; hence, this entity is also called described as a mitochondrial hepatopathy. Electron microscopy confirms structural alteration of mitochondria of the liver, brain and muscle including enlargement in size and fragmentation of cristae. ${ }^{1,7}$ It usually occurs in a previously healthy child. The onset is sudden and usually occurs after an interval of 1-7 days of an apparent recovery from a prodromal viral illness e.g., an upper respiratory infection (in $90 \%$ cases), or chicken pox (in 5-7\% )..$^{2,7}$ In a typical case, persistent vomiting occurs followed by delirium, stupor and disturbances in sensorium to the extent of coma with generalised convulsion. Focal neurologic signs are absent. The clinical spectrum of the syndrome ranges from mild to fatal and subdivided into grade I to $\mathrm{V}$. The liver may be enlarged but jaundice is characteristically absent. ${ }^{7}$ Diagnosis is mostly on clinical suspicion aided by lab findings and liver biopsy. Lab findings include hypoglycemia, elevated serum aminotransferases and $\mathrm{LDH}$, prolonged prothrombin time, elevated serum ammonia and metabolic acidosis. Serum bilirubin and alkaline phosphatase are either normal or only slightly raised. Cerebrospinal fluid shows elevated pressure with low glucose, as a seen in our case. Liver biopsy helps in the diagnosis and in ruling out metabolic or toxic liver disease. It shows microvesicular steatosis with absence of glycogen and minimal inflammation. The term "microvesicular steatosis of the liver" can be seen in conditions like acute fatty liver of pregnancy, Jamaican vomiting sickness, drug toxicity, congenital defects of urea cycle enzymes and alcoholism. ${ }^{11}$ Nonalcoholic steatohepatitis may also show microvesicular type but is usually accompanied by patchy infiltrate and pericellular fibrosis. Nonspecific steatosis does not show inflammation but is usually of a macrovesicular type. Medications usually produce microvesicular fatty change but are often associated with features like cholestasis, eosinophils, hepatocellular necrosis (acetaminophen), inflammation (isoniazid), granulomatous change and regenerative hyperplasia (corticosteroids). Fatty liver of pregnancy shows presence of cholestasis with microvesicular steatosis. Metabolic diseases like organic acidurias, urea cycle defects, fructosemia and fatty acid metabolism defects may present with similar clinical picture. Disorders of oxidative phosphorylation may present a similar picture but are usually seen in older children and jaundice is present. $^{2}$ Thus, in all cases, microvesicular stetosis is important to rule out other causes apart from Reye's syndrome. The treatment is empirical and includes infusion of glucose to restore blood glucose, correction of electrolyte imbalance, control of convulsion, intravenous mannitol and/or corticosteroid to reduce cerebral edema. ${ }^{1,7}$ In grade I disease, the recovery is complete, however, overall mortality is as high as $85 \% .^{1,2}$ In survivors of severe disease, the possibility of neuropsychiatric defects are noted but chronic liver disease has not been reported.

\section{CONCLUSION}

In conclusion, classic Reye syndrome is a clinical entity with characteristic liver biopsy findings and often having a fatal outcome unless it is diagnosed in the early stage. Rey syndrome can present in a child even without history of aspirin or any other drug ingestion.

\section{REFERENCES}

1. Suraj Gupte. Short textbook of pediatrics. 10th ed. New Delhi: Jaypee Brothers; 2004. p.409-10.

2. Balisheri WF. Reye syndrome and "Reye-like" diseases In: Behrman, Kliegman, Jenson, Editors. Nelson textbook of pediatrics. 16th ed. Philadelphia: WB Saunders Company; 2000. p.1214-16.

3. Vinsa-Machin PL, Nunez-Diaz BC. Reye syndrome: a case study in a Cuban provincial hospital from 1990 to 
1996. Rev Neurol 1999 May16-31;28(10):959-61.

4. Casteels-Van Daele M, Van Geet C, Wouters C, Eggermont E. Reye's syndrome revisited: a descriptive term covering a group of heterogenous disorders. Eur J Pediatrics 2000 Sep;159(9):641-8.

5. Bhutta AT, Van Savell H, Schexnayder SM. Reye's syndrome: down but not out. South Med J 2003 Jan;96(1):43-5.

6. Watkins JB, Kartz AJ, Grand RJ. Neonatal hepatitis: A diagnostic approach. Adv Pediatr 1977;24: 399-454.

7. Podolsky DK. Infiltrative, genetic and metabolic diseases affecting liver. In: Kasper DL, Fauci AS, Longo DL, Braunwald E, Hauser SL, Jameson JL, editors . Harrison's principles of Internal Medicine. 16th ed.
New York: McGraw Hill; 2005. p.1869-73.

8. Bajracharya BL, Piya A, Manandhar DS. Reye's syndrome. Kathmandu Univ Med J (KUMJ). 2003 AprJun;1(2):138-40.

9. McIntosh K. Adenoviruses. In: Behrman, Kliegman, Jenson, editors. Nelson textbook of pediatrics. 16th ed. Philadelphia: WB Saunders Company; 2000. p. 994-5.

10. Raphael D. Influenza. In: Kasper DL, Fauci AS, Longo DL, Braunwald E, Hauser SL, Jameson JL, editors . Harrison's principles of internal medicine. 16th ed. New York: McGraw Hill; 2005. p.1066-71.

11. HautekeeteML, DegottC, BenhamouJP.Microvesicular steatosis of the liver. Acta Clin Belg. 1990;45(5):311-26. 